\title{
SKAALAPOHJAINEN NÄKÖKULMA MILES DAVISIN JA GEORGE BENSONIN "SO WHAT"-IMPROVISAATIOISSA
}

Miles Davisin sekstetin "Kind of Blue" -levy (1959) osoitti aikanaan suunnan, josta tuli keskeinen esikuva uutta ilmaisutapaa etsiville muusikoille. Levyn erikoisuus piili siinä, että modaalinen ajattelutapa, joka tuolloin oli jazzissa uutta, hallitsi keskeisesti levyllä esitettäviä teoksia. Pian tämän jälkeen modaalinen ajattelutapa tuli jazzin keskeiseksi osaksi. Tästä ajattelutavasta on luontevaa käyttää nimitystä skaalapohjainen ajattelutapa, sillä erilaiset horisontaaliset asteikkokokonaisuudet pyrkivät olemaan teoksen syvä- eli materiaalirakenteen elementtejä, jotka saavat teosten pintarakenteessa enemmän tai vähemmän asteittaisia, soinnullisia ja vapaampia struktuureja. Tekniikkaa on myöhemmin kehitetty eri suuntiin.

George Bensonin "So What" (1971) on hyvä esimerkki skaalapohjaisesta ajattelutavasta uudemmassa jazzissa. Tulkinta on perusteltua ottaa esille myös siksi, että Benson luo jännitettä ja koloriteettia poikkeamalla ajoittain näkyvästikin molliseptimisoinnun ja doorisen moodin välisestä "ideaalitason" käytännöstä. Bensonin peruskoloriteetit ovat lähinnä mollipentatoninen ja bluesasteikko sekä doorinen ja aiolinen moodi. Tätä värispektriä Benson laajentaa tarvittaessa harmonisen molliasteikon sävelmateriaalilla. Benson vaihtelee myös hienosäikeisesti rockrytmiikan aspekteja ja perinteistä jazzrytmiikkaa tässä teoksessa. 
Ennen George Bensonin "So What" -improvisaation (1971) tarkastelua selvitän tonaalisuuden ja modaalisuuden käsitteitä sekä suhteutan skaalapohjaisen näkökulman tätä taustaa vasten. Samalla tuon esille Miles Davisin sekstetin "Kind of Blue" -levyn (1959) merkitystä ja selvitän levyllä olevan "So What" -soolon skaalapohjaista perustaa. Perustelen valintaa sillä, että Davisin "So What" -soolossa tulee selkeästi esille eräs jazzin "ideaalitason" pragmatiikka: molliseptimisoinnun (m7) ja doorisen moodin välinen yhteys.

\section{Tonaalisuuden ja modaalisuuden käsitteestä}

Tonaalisuudella tarkoitan sen laajennettua merkitystä. Laajasti ajatellen tonaalisuudella ymmärrän kaikkea sitä musiikkia, jonka sävelillä on jokin hierarkia ja tässä hierarkiassa tonaalinen keskus on voimakkain tekijä. Tonaalisella keskuksella tarkoitan musiikillisen tapahtuman "painovoimakeskusta". Suppeammin ilmaistuna tonaalisuus perustuu toonika- ja dominanttitehon väliseen jännitystilaan, joka purkautuu dominanttisointuun sisältyvän johtosävelen (alajohtosävel) kautta perussäveleen (-sointuun) tai sitä edustavaan säveleen (sointuun). Johtosävelen ja perussävelen välinen etäisyys on tällöin pieni sekunti.

Tonaalisuuteen liittyy sointujen funktionaalisuus. Funktionaalisuuden mukaan sointua tarkastellaan oleellisimmin sen mukaan, miten kukin sointu suhtautuu sävellajiin ja sen tonaaliseen keskukseen, toonikaan. Eurooppakeskeisesti modaalisella musiikilla on yleensä ymmärretty ns. kirkkosävellajeille perustuvaa musiikkia. Määrittelen modaalisuuden laajemmin. Modaalista musiikkia on mielestäni kaikki se musiikki, mikä ei ole suppeassa mielessä tonaalista. Liitän modaalisuuteen edelleen joko soinnuttomuuden tai omalaatuisen soinnun käytön. Näin laajennettu tonaalisuus ja laajennettu modaalisuus ovat lähellä toisiaan, mutta tonaalisuuden alueella sointujen funktionaalisuus ja modaalisuuden piirissä joko soinnuttomuus tai omalaatuinen soinnun käyttö ovat erottavia tekijöitä. Näin skaalapohjainen ajattelutapa liittyy mielestäni oleellisesti modaalisuuteen ja tätä kautta omalaatuiseen melodiankäyttöön.

\section{Davisin "So What": molliseptimisointu ja doorinen moodi}

Skaalapohjainen ajattelutapa sopii hyvin teoksiin, joissa teoksen harmoninen liike on hidas. Tällöin jopa yhden tai kahden soinnun käyttö teoksen 
perustana on hyvinkin luonteenomaista. Sointuja saatetaan käyttää kiinnittämättä huomiota niiden funktioharmonisiin suhteisiin. Varsinkin skaalapohjaisen ajattelutavan alkuaikoina oli yhtäläisyyksia tietyn sointu- ja skaalatyypin välillä.

Seuraava Miles Davisin "So What" -tulkinta (1959) verifioi tämän yhteyden: molliseptimisoinnun $(\mathrm{m} 7)$ ja doorisen moodin välisen yhteyden. Sointumerkinnät - Dm7 ja $E^{b} \mathrm{~m} 7$ - symbolisoivat siis teoksen syvärakenteessa olevia asteikkoja. ${ }^{1}$ Davisin käyttämä skaalamateriaali perustuu D- ja $\mathrm{E}^{\mathrm{b}}$-doorisille moodeille. Improvisaation alku on esitetty nuottiesimerkki l:ssä.

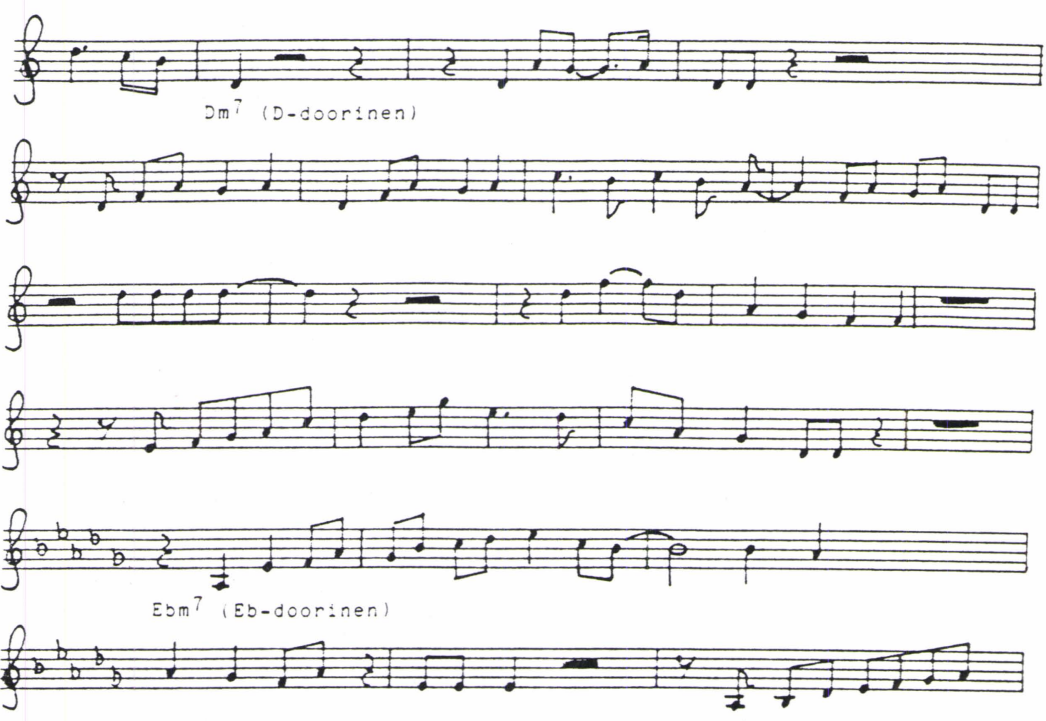

Esim. 1

George Bensonin "So What": Useiden asteikkojen värispektri

Benson avaa improvisaationsa (tahdit 1-5) D-mollipentatonisen tai Dbluesasteikon sävelmateriaalilla (Esim. 2) ${ }^{2}$.

\footnotetext{
${ }^{1}$ Liukon transkriptio. Kawrza kuvaa Davisin ja Adderleyn improvisaatiotekniikkaa kirjassa Jazz Forschung/Jazz Research 18 (1986), 9-16. Kind on Blue -levyn syntyvaiheita selvitetään Carrin Miles Davis -kirjassa, Carr 1985, 134-135.

${ }^{2}$ Tim Mayn nuotinnus (kaikki Bensonin So What -näytteet), down beat 1972, June , 39-41.
} 

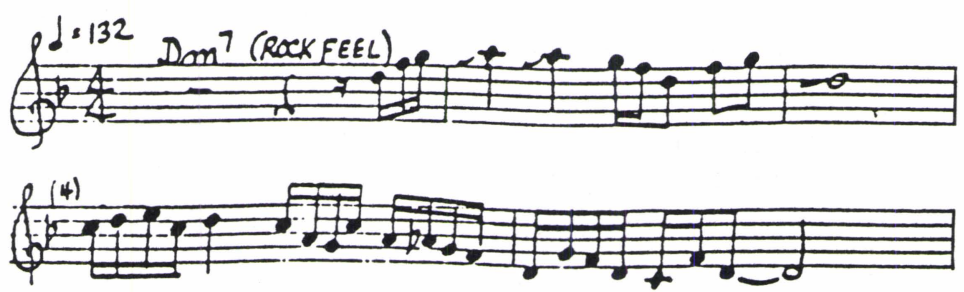

Esim. 2 (tahdit 1-5)

Tahtien syvärakenteessa oleva skaalamateriaali koostuu F-pentatonisen asteikon V moduksen sävelistä. Tällöin as-sävel analysoidaan lomasäveleksi ja e-sävel lisäsäveleksi. Jos as-sävel tulkitaan skaalan säveleksi, asteikkko painottuu e-sävelellä täydennetyn D-bluesasteikon suuntaan (Esim.3).

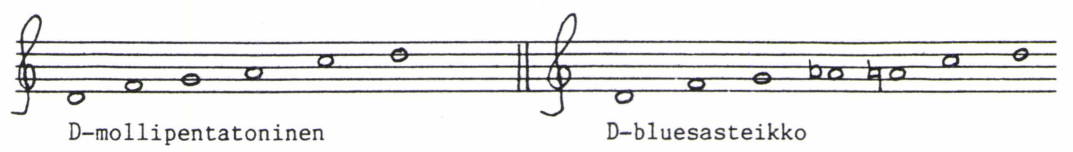

Esim. 3

Nuottiesimerkin 4 alue (tahdit 6-7) voidaan analysoida 7. tahdin puoliväliin asti a-sävelellä täydennetyksi C-mollipentatonisen asteikon sävelmateriaaliksi.

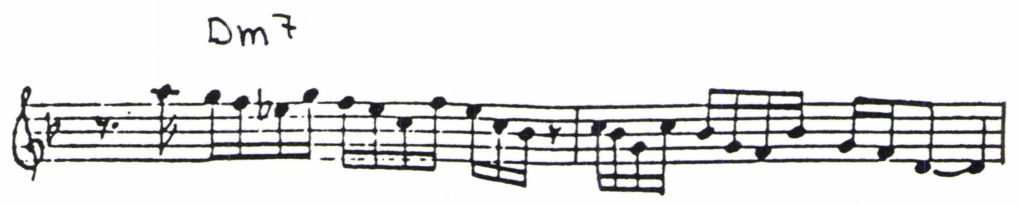

Esim. 4 (tahdit 6-7)

Eb-pentatonisen asteikon V moduksen eli C-mollipentatonisen asteikon sävelmateriaali on nuottiesimerkin 5 mukainen.

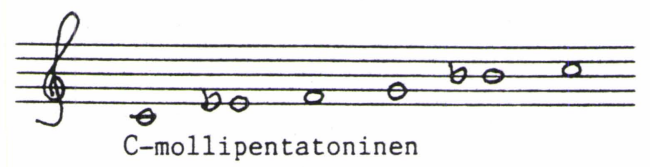

Esim. 5 
Tämän osan melodinen aihe, jota siis käsitellään C-mollipentatonisen asteikon piirissä, on nuottiesimerkin 6 mukainen. Kokoaskeleen alempana sijaitseva improvisoinnin tonaliteetti (c-keskeinen) häilyttää perustonaliteettia (d-keskeinen).

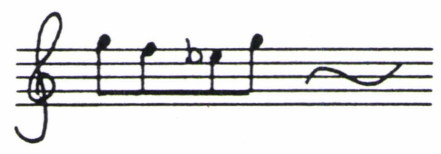

Esim. 6

7. tahdin puolivälistä alkaen Benson siirtyy myös improvisoinnissa vallitsevan perustonaliteetin alueelle, D-mollipentatoniselle sävelmateriaalille.

Hiukan myöhemmin nuottiesimerkissä 7 (tahdit 9-11) teoksen harmoninen perusta on muuttunut $\mathrm{E}^{\mathrm{b}} \mathrm{m} 7$-soinnun alueelle, jossa Benson operoi Ebmollipentatonisen tai $\mathrm{E}^{\mathrm{b}}$-bluesasteikon tunnelmassa.

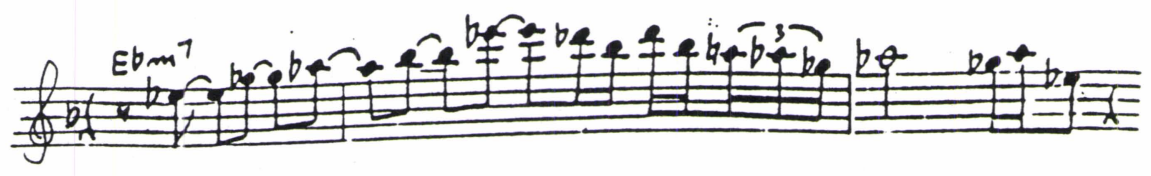

Esim. 7 (tahdit 9-11)

$\mathrm{G}^{\mathrm{b}}$-pentatonisen asteikon $\mathrm{V}$ moduksen eli $\mathrm{E}^{\mathrm{b}}$-mollipentatonisen asteikon käyttö ulottuu ainakin a-sävelelle asti. Koko näyte sisältyy kyseisen pentatonisen asteikon piiriin, jos a-sävel analysoidaan loma- tai lisäsäveleksi. $E^{b}$-bluesasteikko on yhtä hyvin koko alueen sävelmateriaalina. (Ks. nuottiesimerkki 8).

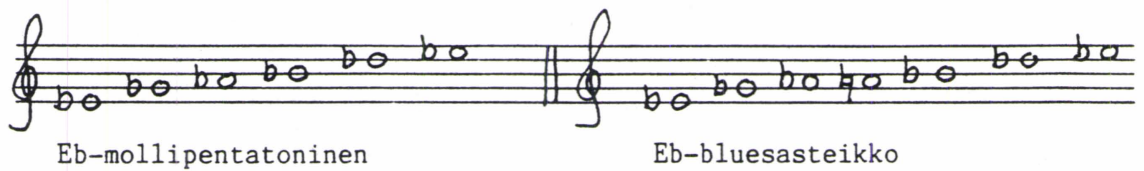

Esim. 8

Nuottiesimerkki 9 sisältää tahdit 12-16. 

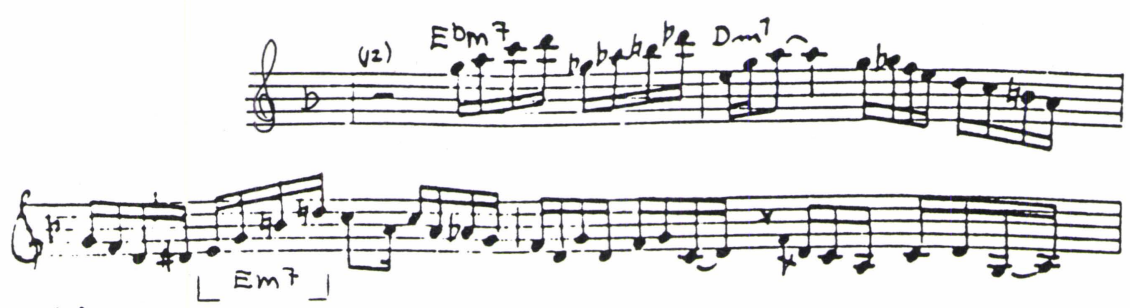
$\left\{\begin{array}{l}(6) \\ 2:==\end{array}\right.$

Esim. 9 (tahdit 12-16)

13. tahdista alkaen Benson palaa Dm7-soinnun väriin. $E^{b}$-mollitonaliteetti on jälleen häilytetty 12 . tahdissa: F- ja Fb-pentatonisten asteikkojen sävelet. Pintarakenteessa esiintyvissä reaalisissa sekvenssikuvioissa ei esiinny asteikkojen perussäveliä. Improvisaation tonaliteetti voidaan ajatella luontevasti $\mathrm{D}$ - ja $\mathrm{D}^{\mathrm{b}}$-mollitonaliteeteissä: F-pentatonisen asteikon $\mathrm{V}$ modus $=$ $\mathrm{D}$-mollipentatoninen asteikko ja $\mathrm{Fb}^{\mathrm{b}}$-pentatonisen asteikon $\mathrm{V}$ modus vastaavasti $\mathrm{Db}$-mollipentatoninen asteikko.

13. tahdista alkaen siirrytään D-doorisen moodin alueelle, jonka karaktääri näkyy pintarakenteessa 14 . tahdin puoliväliin asti. Tällöin ges- ja dissävelet ovat hajasäveliä (lomasäveliä). Tässä vaiheessa huomio kiinnittyy aluksi asteittaisempaan melodiakulkuun sekä doorisen moodin II asteen soinnun arpeggioon (Em7). 14. tahdin puolivälistä alkaen painottuu selkeimmin D-bluesasteikon muoto.

Nuottiesimerkki 10 sisältää tahdit 17-20.

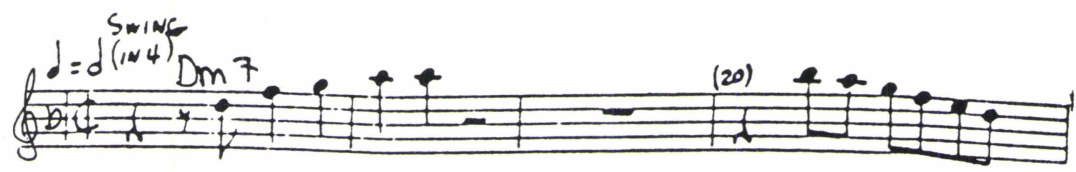

Esim. 10 ( tahdit 17-20)

17. ja 18. tahti painottuvat D-mollipentatonisen asteikon alueelle, josta csävel puuttuu pintarakenteessa. Melodinen motiivi on peräisin improvisaa- 


\section{Vesa Liukko}

tion alusta (tahdit 1-2). 20. tahdissa koloriteettiä on lisätty D-aiolisen moodin suuntaan, joskin pintarakenne esittää moodin heksakordia.

Harmonisen molliasteikon $\mathrm{V}$ asteen sointuarpeggion käyttö ilmenee jatkossa mm. esimerkkinäytteessä 11 (tahdit 21-22).

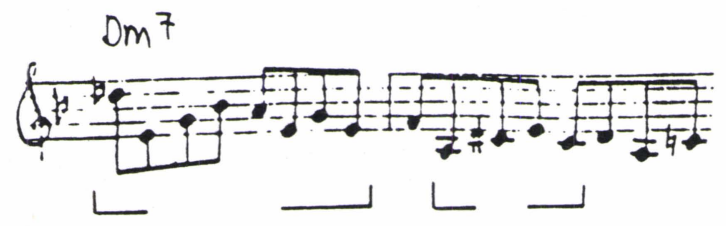

Esim. 11 (tahdit 21-22)

Syvärakenteessa oleva skaalamateriaali on muuttunut harmonisen D-molliasteikon sävelistöön viimeistä 1/4-aika-arvoa lukuunottamatta. Asteikon karaktääri on ilmaistu pääasiallisesti $\mathrm{V}$ asteen sointuarpeggiolla: 21. tahdissa A7b9 - ja 22. tahdissa A-soinnut. 22. tahdin lopussa koloriteetti muuttuu D-doorisen moodin suuntaan.

VI asteen sointuarpeggion käyttö ilmenee heti jatkossa esimerkkinäytteessä 12 (tahdit 23-25).

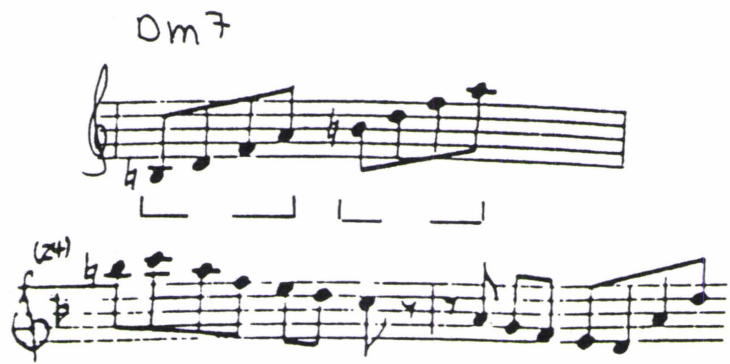

Esim. 12 (tahdit 23-25)

23. tahdissa Benson liikkuu D-doorisen moodin VI asteen soinnun miljöössä: Bm7b5-sointu. 24. tahdista alkaen arpeggiokulut tasapainotetaan skalaarisemmalla liikkeellä.

VII asteen sointuarpeggion käyttö näkyy mm. esimerkkinäytteessä 13 (tahdit 26-29). 


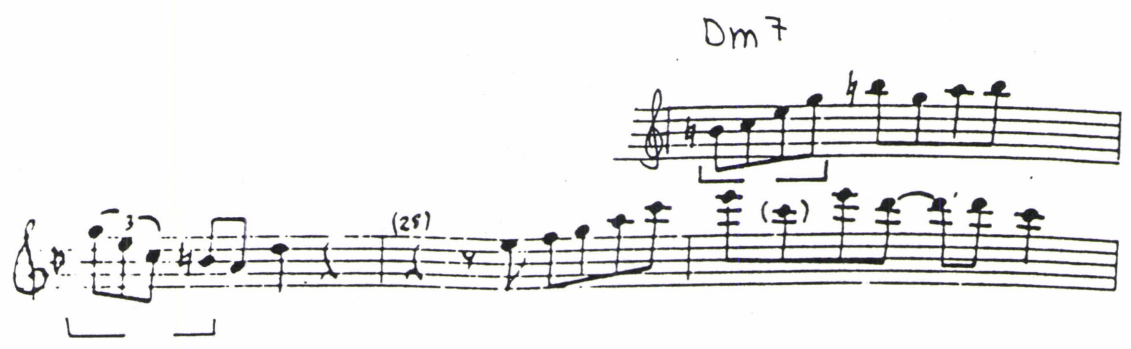

Esim. 13 (tahdit 26-29)

D-doorisen moodin vaikutus ulottuu myös näihin tahteihin. Huomio kiinnittyy erityisesti kahteen asiaan. Ensiksikin, moodin käyttö toteutuu soinnullisessa mielessä selväpiirteisesti VII asteen soinnun käyttönä: 26. tahdissa ylöspäinen Cmaj7/B- ja 27. tahdissa alaspäinen, mutta eri tavalla rytmitetty Cmaj7/B-arpeggiokulku. Toiseksi, 28. tahdista alkaen doorista sekstiä ei käytetä pintarakenteessa.

Hiukan myöhemmin, esimerkissä 14 (tahdit 35-36), Eb-aiolisen moodin ilmiasu on esitetyssä muodossa. $\mathrm{E}^{\mathrm{b}} \mathrm{m} 7$-sointu on ilmaistu Eb-aiolisella moodilla, johon on sijoitettu yksi lomasävel (g).

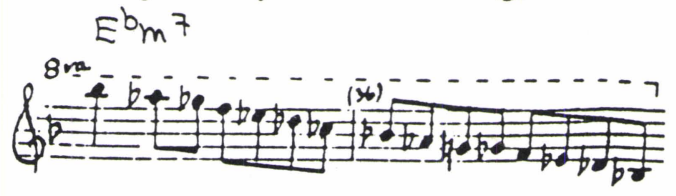

Esim. 14 (tahdit 35-36)

Polymodaalinen ajattelutapa ilmenee esimerkkinäytteessä 15 (tahdit 51-53) mielenkiintoisesti siten, että Bensonin käyttämä sävelmateriaali sijoittuu syvärakenteessa pääasiallisesti D-doorisen ja D-aiolisen moodin sekä harmonisen D-molliasteikon alueille seuraavasti:

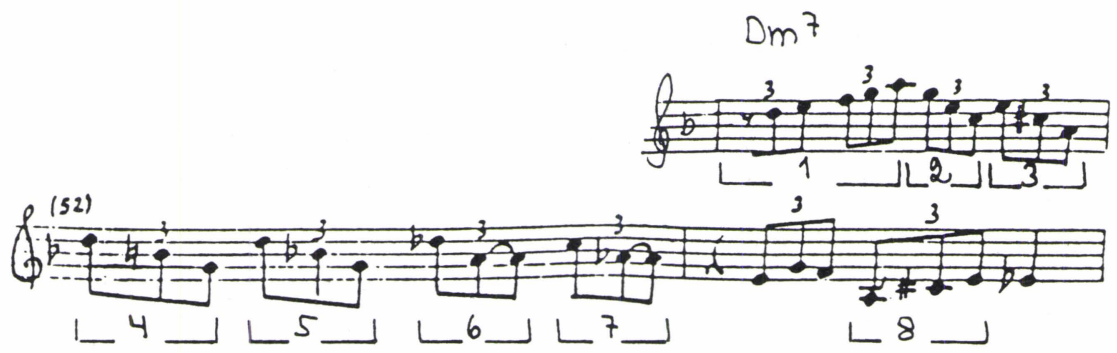

Esim. 15 (tahdit 51-53) 
1) D-doorisen tai D-aiolisen moodin pentakordi: D-mollipentakordi

2) D-doorisen tai D-aiolisen moodin VII asteen soinnun alaspäinen sointuarpeggio: C-sointu,

3) Harmonisen D-molliasteikon $V$ asteen soinnun alaspäinen sointuarpeggio: A-sointu,

4) D-doorisen moodin IV asteen soinnun alaspäinen sointuarpeggio: G-sointu,

5) D-aiolisen moodin IV asteen soinnun alaspäinen sointuarpeggio:

Gm-sointu,

6) Harmonisen D-molliasteikon kvintti (a) ja septimi (des = cis). Intervalli viittaa $\mathrm{V}$ asteen sointuun (Vrt. 3. ja 8. kohta),

7) Harmonisen $D^{b}$-molliasteikon kvintti (as) ja septimi (c), intervalli on puolta sävelaskelta alempana sijaitseva edellisen intervallin (6. kohta) reaalinen sekvenssikuvio. Harmoninen D-molliasteikko palautuu syvärakenteessa 53. tahdin alusta. Sointuun orientoitunut painotus näkyy $\mathrm{mm}$. seuraavasti:

8) Harmonisen D-molliasteikon V asteen soinnun ylöspäinen sointuarpeggio: A-sointu,

Pentatonisen ja doorisen moodin käyttö ilmenee esimerkissä 16 (tahdit 6061) mielenkiintoisesti.

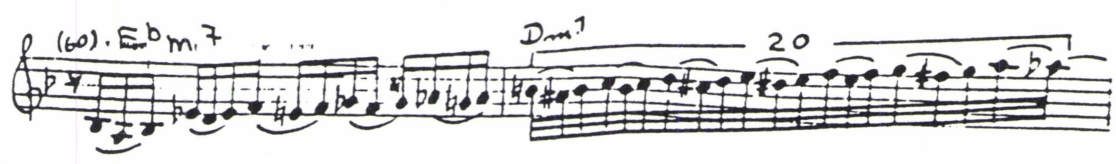

Esim. 16 (tahdit 60-61)

60. tahdissa melodinen motiivi muodostuu $\mathrm{E}^{\mathrm{b}}$-mollipentakordin sävelille ja niiden alajohtosävelille (ks.nuottiesimerkit 16 ja 17).

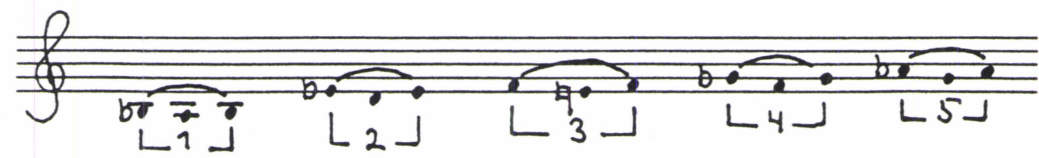

Eb-mollipentakordi

Esim. 17 
61. tahdissa sama ajatus jatkuu D-doorisen moodin sävelmateriaalissa nopeammin aika-arvoin (ks. nuottiesimerkit 16 ja 18).

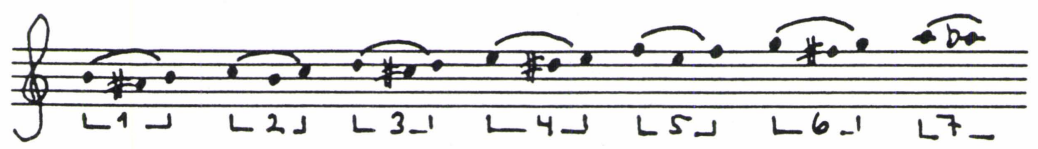

D-doorinen

Esim. 18

Improvisaation lähestyessä loppuaan Benson iskee uuden elementin, repetitiomotiivien käytön bensonimaiseen tapaan, joka on esitetty nuottiesimerkissä 19 (tahdit 105-121).

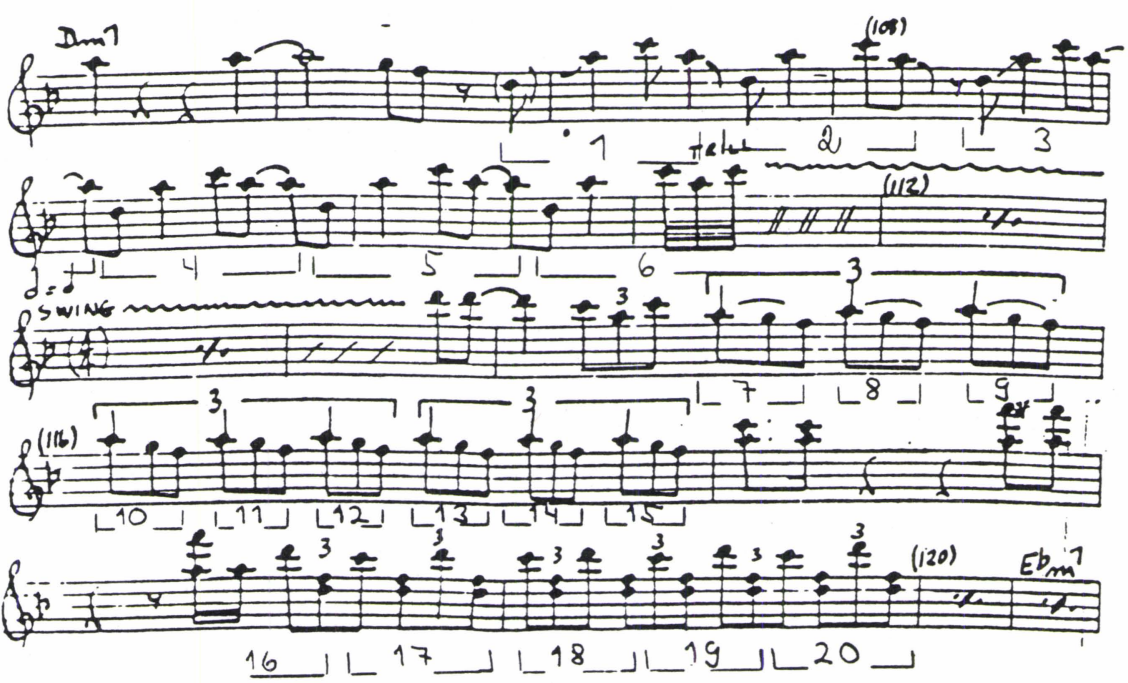

Esim. 19 (tahdit 105-121)

Skaalamateriaali muodostuu D-mollipentatonisen asteikon sävelistä.

1) Ensimmäinen repetitiomotiivi muodostuu seuraavista sävelistä: ks. esimerkkinäytteen numerot 1-5.

Numerolla 6 merkitty motiivi muuntuu lopussa jääden pitkäksi trilliksi: tahdit 111-114.

2) Täysin uusi repetitiomotiivi on merkitty näytteessä 19 numeroilla 7-15. 
3) Kolmas hallitseva motiivi on merkitty näytteessä 19 numeroilla 16-20. Tämä motiivinen ajatus, septimin ja perussävelen vuorottelu, onkin johtotähtenä esimerkkinäytteen 19 loppuun saakka.

\section{Lähteitä}

Baker, David

1974 Jazz Improvisation. Chicago.

Baker, David

1980 The Jazz Style of Miles Davis. Printed in U.S.A.

Baker, David

1982 Jazz Pedagogy. USA.

Baker, David

1983 Jazz Improvisation. USA.

Carr, Ian

1985 Miles Davis. London.

Coker, Jerry:

1964 Improvising Jazz. New Jersey.

Coker Jerry:

1978 The Jazz Idiom. Prentice Hall, Inc. Englefood Cliffs, New Jersey.

Gonda, Janos

1973 Problems of Tonality and Function in Modern Jazz Improvisation. Jazz Forschung/Jazz Research 3/4 1971/72. Wien, 194-205.

Haerle Dan

1980 The Jazz Language. Printed in U.S.A.

Kawrza, Johann

1986 Julian "Cannoball" Adderley (1928-1975). Seine Improvisationstechnik in der Zeit seines Schaffens bei Miles Davis. Jazz Forschung/Jazz Research 18. Graz, 9-66.

Liukko, Vesa

1989 Sointupohjaisesta skaalapohjaiseen: ajattelutavan muutos jazzissa. Kansaperinteen, erityisesti kansanmusiikin lisensiaattityö (Tampereen yliopisto).

May, Tim

1972 db music workshop-down beat, June 8, 39-41. 
Mehegan, John

1959 Jazz Improvisation 1. New York.

Moodi - Otavan iso musiikkitietosanakirja 4.

1978 Keuruu.

Oramo Ilkka

1977 Modaalinen symmetria. Helsinki.

Pass, Joe \& Thrasher, Bill

1970 Joe Pass Guitar Style. California.

Persichetti, Vincent

1978 Twentieth Century Harmony. USA.

Russell, George

1971 The Lydian Chromatic Concept of Tonal Organization. New York.

Tirro, Frank

1977 Jazz: A History. Toronto. 